\title{
De la oposición política en el discurso: la reformulación polémica en la retórica guerrillera colombiana ${ }^{1}$
}

\section{Giohanny Olave ${ }^{2}$}

Recibido: 2015-07-11

Enviado a pares: 2015-07-15
Aprobado por pares: 2015-08-27

Aceptado: 2015-09-22

DOI: 10.5294/pacla.2016.19.2.3

Para citar este artículo / To reference this article / Para citar este artigo

Olave, G. (Junio de 2016). De la oposición política en el discurso: la reformulación polémica en la retórica guerrillera colombiana. Palabra Clave, 19(2), 398-421. D0I: 10.5294/ pacla.2016.19.2.3

\section{Resumen}

En este artículo se analiza el uso del procedimiento retórico de la reformulación polémica en el discurso de la guerrilla de las Fuerzas Armadas Revolucionarias de Colombia. Se conformó un corpus con los artículos publicados en la revista virtual Resistencia, ediciones 2010 a 2012, consultadas en los sitios web del grupo insurgente, y se extrajeron categorías emergentes por análisis inductivo. Como resultados, se describen los tipos de reformulación que aparecen en la muestra y su coocurrencia con negaciones polifónicas en función de refuerzo. Las conclusiones apuntan a interpretar la reformulación como un modo de oponerse al Gobierno central, por medio de la polémica como modalidad argumentativa. En este caso, la reformulación es clave en el esfuerzo por construir formas de divergencia política en el discurso, porque refuerza el distanciamiento entre los actores e involucra el problema de la verdad en los discursos del conflicto armado interno.

1 Este artículo es un avance de una tesis en curso sobre la retórica de la oposición política guerrillera en el conflicto armado colombiano (2010-2012), investigación dirigida por Elvira Narvaja de Arnoux, codirigida por Mireya Cisneros Estupiñán, en el Doctorado en Letras de la Universidad de Buenos Aires, y financiada por el Consejo Nacional de Investigaciones Científicas y Técnicas (Conicet) (2012-2017).

2 Universidad de Buenos Aires/Conicet. Argentina. olavearias@gmail.com 


\section{Palabras clave}

Conflicto armado colombiano; FARC, marcadores reformulativos; discurso polémico (Fuente: Tesauro de la Unesco).

\section{From Political Opposition in Speech: The Polemic Reformulation in Colombian Guerrilla Rhetoric}

\section{Abstract}

This article analyzes the use of rhetorical polemic reformulation process in the speech of the guerrillas of the Revolutionary Armed Forces of Colombia. A corpus with articles published in the online journal, Resistencia, 2010-2012 editions, consulted the websites of the insurgent group, and emergent categories were extracted by inductive analysis. As a result, reformulation types that appear in the sample and their co-occurrence with polyphonic denials described reinforcing function. The findings point to interpret the reformulation as a way to oppose the central government, through the controversial and argumentative mode. In this case, reformulation is key in the effort to build forms of political divergence in discourse, because it reinforces the distance between the actors and involves the problem of truth in the speeches of the internal armed conflict.

\section{Keywords}

Armed conflict in Colombia; FARC; reformulation markers; controversial speech (Source: Unesco Thesaurus). 


\section{Sobre a oposição política no discurso: a reformulação polêmica na retórica guerrilheira colombiana}

\section{Resumo}

Neste artigo, analisa-se o uso do procedimento retórico da reformulação polêmica no discurso da guerrilha das Forças Armadas Revolucionárias da Colômbia. Conformou-se um corpus com os artigos publicados na revista virtual Resistencia, edições de 2010 a 2012, consultadas nos sites do grupo insurgente, e extraíram-se categorias emergentes por análise indutiva. Como resultados, descrevem-se os tipos de reformulação que aparecem na amostra e sua co-ocorrência com negações polifônicas em função de reforço. As conclusões apontam a interpretar a reformulação como um modo de se opor ao Governo central por meio da polêmica como modalidade argumentativa. Nesse caso, a reformulação é fundamental no esforço por construir formas de divergência política no discurso, porque reforça o distanciamento entre atores e envolve o problema da verdade nos discursos do conflito armado interno.

\section{Palavras-chave}

Conflito armado colombiano; FARC; marcadores reformulativos; discurso polêmico (Fonte: Tesauro da Unesco). 
En este artículo, ${ }^{3}$ se analiza el uso del procedimiento retórico de la reformulación polémica en el discurso de la guerrilla de las FARC (Fuerzas Armadas Revolucionarias de Colombia). En la actualidad, este grupo insurgente tiene una presencia importante en el territorio rural colombiano, desde donde opera con una estructura política y militar consolidada y reconocida por las Fuerzas Armadas del Estado, que confrontan a los guerrilleros regularmente, en el esquema de contrainsurgencia en guerra de guerrillas.

Para abordar el procedimiento de la reformulación polémica en el discurso de esa guerrilla, es necesario, primero, establecer una diferencia semántica básica con la reformulación no polémica. Empecemos por notar, en un ejemplo arbitrario, que los enunciados A y B comparten una estructura formal del tipo $X$ (conector) $X_{1}$, donde la segunda parte $\left(X_{1}\right)$ retoma la primera $(X)$, de modos particulares:

(A) La policía, o sea, la autoridad encargada del orden público.

(B) La policía, o sea, los asesinos a sueldo del Estado.

Donde X es "la policía”

X 1 es "la autoridad encargada del orden público"

$\mathrm{X}_{1 \mathrm{~B}}$ es "los asesinos a sueldo del Estado"

Mientras que en (A) la relación semántica puede enunciarse como $X \leq X_{1 A}$ (porque la segunda parte explica la primera a través de una especificación), el caso de (B) no es el de una equivalencia explicativa o una paráfrasis, sino más bien el de una reorientación argumentativa: $X_{1 в}$ nо explica, sino que propone un punto de vista divergente que ejerce una desacreditación sobre lo reformulado, así: $-X \leq+X_{1 B}$. Las enunciaciones que relacionan de este modo general segmentos con marcadores discursivos o de aposiciones ${ }^{4}$ son denominadas reformulaciones no parafrásticas (Garcés, 2008; Kotschi, 2001; Rossari, 1997; Roulet, 1987). Garcés

3 Una versión preliminar de este texto fue presentada en el II Congreso Internacional de Retórica e Interdisciplina: la cultura y sus retóricas (Olave, 2015b). La ponencia se encuentra inédita.

4 Incluyo aquí las aposiciones como construcciones dentro de las cuales es posible encontrar reformulaciones polémicas en el corpus de estudio, pero no serán objeto de análisis en este artículo y su tratamiento queda pendiente. 
(2006, pp. 659-660) sintetiza que la reformulación no parafrástica se caracteriza por introducir un cambio de perspectiva enunciativa a través de una reinterpretación (de ahí su carácter polifónico), establecer relaciones jerárquicas de igualdad o de subordinación entre los segmentos reformulante y reformulado y orientar el significado a través de los marcadores de reformulación, que adquieren valor argumentativo en cada contexto de enunciación.

El estudio de la reformulación como fenómeno textual ha estado inscrito en el extenso campo de la investigación sobre conectores y marcadores discursivos. Con diferentes matices y especificidades, ellos son entendidos como partículas gramaticales que guían inferencias para la interpretación de lo expresado, según diversas condiciones situacionales, interaccionales y cognitivas; efectos que desbordan los alcances teóricos de las gramáticas oracionales (Bosque, 2001; Briz, 2008; Fuentes, 2009; Garcés, 2008; Montolío, 2001; Pons, 2000; Zorraquino y Portolés, 1999). ${ }^{5}$ Los trabajos más recientes (García Negroni, 2014; Loureda y Acín, 2010) han analizado los intereses de las discusiones actuales y han resaltado en ellas una orientación multidimensional: desde el abordaje de la gramaticalización diacrónica de los marcadores, su dimensión pragmática y enunciativa, hasta enfoques sociocognitivos sobre el uso de estas partículas.

En esta tradición, convergen múltiples esfuerzos por clasificar los marcadores de acuerdo con diferentes criterios taxonómicos. Es en esas clasificaciones, precisamente, donde aparece la reformulación como un tipo de función que pueden cumplir algunas partículas como "es decir", "o sea" y "esto es", entre muchas otras a las que se han dedicado investigaciones específicas en español (Casado, 1991; Fuentes, 1993; Galán, 1998; Garcés, 2008; Vercruysse, 2009).

La clasificación de Zorraquino y Portolés (1999, p. 4124) incluye, entre sus cinco grupos de marcadores, los denominados reformuladores como

5 Las características de los marcadores discursivos son las siguientes: 1) son unidades lingüísticas invariables; 2) están al margen de la predicación oracional; 3) enlazan el miembro del discurso en el que se encuentran con otro precedente, expreso o implícito; 4) permiten guiar, según sus características semánticas y pragmáticas, las inferencias que se realizan en la comunicación (Zorraquino y Portolés, 1999). 
aquellos que "presentan el miembro del discurso en el que se encuentran como una nueva formulación de lo que se quiere decir con un miembro anterior”. Habría, además, cuatro subtipos de reformuladores: explicativos ("es decir", etcétera), de rectificación ("mejor dicho", etcétera), de distanciamiento ("de todos modos", etcétera) y recapitulativos ("en conclusión”, etcétera).

Fuentes (2009, p. 378), por su parte, presenta el grupo de los "reformulativos" como una "función discursiva [para] introducir un nuevo enunciado que modifique lo anterior". Casado (1991, p. 65) refiere, asimismo, la reformulación como un tipo de "función textual", donde incluye similares ejemplos de las dos fuentes anteriores. En la clasificación de Pons (2000), los reformulativos son marcadores metadiscursivos con función textual, diferentes de la función lógica en la que clasifican al grupo de los marcadores argumentativos. Finalmente, en algunas propuestas, como la Loureda y Acín (2010), no se incluye el nombre de marcadores de reformulación dentro de sus grupos: "modalización”, "marcación” y "control del contacto", si bien se hace referencia a algunos conectores con función argumentativa dentro del segundo grupo. Esta propuesta es muy cercana a la de Briz (2008); pero, en las categorías que este último autor propone, incluye la "función reformuladora", independiente de la argumentativa.

En cuanto a las clasificaciones de los marcadores de reformulación no parafrástica en particular, Garcés (2006, p. 657) recoge las distinciones hechas por Rossari (1997) y Kotschi (2001) para identificar tres tipos, según el grado de distanciamiento entre los segmentos reformulante y reformulado: 1) recapitulación (grado mínimo), 2) reconsideración (grado medio) y c) separación (grado máximo). En la propuesta de Cortés y Camacho (2005), para el discurso oral, no es el distanciamiento sino la relación jerárquica la que determinará la siguiente tipología: concreción propia, resumen, generalización, relieve, restricción y rectificación.

Los estudios que siguen estas taxonomías en las que aparece la reformulación coinciden en presentarla como un procedimiento de organización del discurso o un retorno a lo ya dicho (a través de procedimientos que pueden ser parafrásticos o no parafrásticos, como ya fue explicado), 
para realizar adecuaciones entre lo comunicado y la intención del hablante, y ayudarle al interlocutor en el trabajo interpretativo. Estas visiones se inscriben predominantemente en una perspectiva pragmática de la interlocución, regida por un contrato implícito de cooperación comunicativa entre los hablantes (Grice, 1989 [1975]); Wilson y Sperber, 2006). En este sentido, resulta pertinente la crítica de Charolles (1987, pp. 100-101): “Parece difícil aceptar que todas las reformulaciones se originen en una voluntad de cooperación. Esta concepción, excesivamente bondadosa al respecto de los locutores, no es defendible dado lo que se conoce sobre las operaciones implicadas en la producción verbal [traducción propia]”.

Podemos añadir, entonces, que estos estudios no introducen una dimensión de orden polémico en la reformulación, es decir, un análisis de la inscripción de fuerzas divergentes entre lo reformulante y lo reformulado, en entramados polifónicos donde una voz disidente retome a la otra para cuestionarla y para polemizar con ella ante la opinión pública. Steuckardtl (2007, 2009), desde el análisis del discurso en la línea de la retórica argumentativa, propone llamar a esta operación "reformulación polémica":

\begin{abstract}
[...] una formulación de un estado de cosas que ya había sido iniciado por el oponente, a menudo conservando sus construcciones sintácticas y la mayoría de sus palabras utilizadas, pero con una orientación argumentativa totalmente opuesta, a través de ese mismo material léxico. Como en el refrán del que "va por lana y vuelve trasquilado", la víctima de esta operación se ve atacada en su propio terreno, con las estructuras lingüísticas que ella misma había planteado [traducción propia]. ${ }^{7}$
\end{abstract}

Los avances de los estudios sobre la polémica (Amossy, 2014; Angenot, 1982; Kerbrat-Orecchioni, 1980; Plantin, 2003) ofrecen un marco productivo para el estudio de esa reformulación orientada. Lo polémico es

\footnotetext{
6 "Il paraît difficile de considérer que toutes les reformulations sont commandées chez celui qui les produit par une volonté de coopération. Cette conception excessivement charitable pour les locuteurs n’est guère défendable étant donné ce que l'on sait des opérations intervenant dans une tâche de production verbale" (Charolles, 1987, pp. 100-101).

7 “[...] une opération de formulation sur un état des choses qui avait été initiée par l'adversaire ainsi que, souvent, le moule syntaxique et plusieurs des mots qu'il a lui-même utilisés, mais elle y coule un matériau lexical d'orientation argumentative tout opposée. La victime de cette récupération se trouve, comme l’arroseur arrosé, attaquée sur son propre terrain, avec les structures phrastiques qu'elle a elle-même posées” (Steuckardtl, 2007, p. 73).
} 
un tipo de modalidad ${ }^{8}$ argumentativa que rige aquellos intercambios verbales, donde predominan la descalificación del adversario, la polarización o división social y la dicotomización de puntos de vista en la esfera pública (Amossy, 2014), además de una implicación del interlocutor en la enunciación del locutor, para ponerlo en cuestión (Charaudeau y Maingueneau, 2005, pp. 446-447). Con este enfoque, ha sido posible estudiar la inscripción de la oposición política en el discurso de los actores del conflicto armado colombiano, concentrándose en la dimensión retórica, como uno de sus aspectos más relevantes (Olave, 2011, 2012, 2013a, 2013b, 2014, 2015a, 2015b; Olave y Cediel, 2015).

En este artículo, presentaremos tres usos de la reformulación polémica (definitoria, modal y contrastiva) y una estrategia retórica de refuerzo de esos usos (la negación polifónica) en el discurso de las FARC. Diferenciaremos esos modos en el apartado de resultados y presentaremos, en las conclusiones, la relación de este procedimiento retórico con la inscripción de la oposición política en el discurso, dentro del marco de la polémica como modalidad argumentativa (Amossy, 2014).

\section{Método}

Se conformó un corpus con los artículos publicados en la revista virtual Resistencia, en sus ocho ediciones aparecidas durante 2010 a 2012. Se trata del órgano oficial de difusión de las FARC, publicado desde 1978, con periodicidad irregular. El listado de revistas es el siguiente:

8 La "modalidad argumentativa", en la teoría de la polémica que seguimos aquí, no debe confundirse con el concepto de 'modalización' y sus diferentes enfoques teóricos, que convergen en una cierta "actitud del sujeto hablante respecto de su propio enunciado” (Charaudeau y Maingueneau, 2005, pp. 394). Según Amossy (2014, p. 70), “la polémica no es un género de discurso (ella atraviesa los tipos y géneros de discurso), sino una modalidad argumentativa entre otras" [traducción propia], es decir, un tipo de intercambio social, caracterizado por el conflicto entre puntos de vista divergentes. Desde el punto de vista de Meunier (1974, citado por Charaudeau y Mainguenau, 2005, p. 393), correspondería a una "modalidad de enunciado", no de enunciación; y Desde el punto de vista de Querler (1996, citado por Charaudeau y Mainguenau, 2005, p. 393), a un tipo de "modalidad intersubjetiva”. Si bien sería posible realizar un análisis de las diferentes modalizaciones que aparecen en el corpus conformado, e inclusive ponerlo en relación con la modalidad polémica, ese análisis no es el objetivo de este artículo. Sobre la modalización en los discursos políticos involucrados en el conflicto armado colombiano, puede leerse el trabajo de Olave y Cediel (2015). 
- Revista de mayo de 2010, en homenaje a "Martín Caballero" (60 páginas).

- Revista de junio de 2011: "Alfonso Cano, el comandante de las FARC, responde al diario español Público" (36 páginas).

- Revista de julio de 2011: "Ala Política Agraria de mentiras de la oligarquía, oponemos una efectiva Política Agraria Revolucionaria que cambie de raíz la estructura social del campo colombiano” (36 páginas).

- Revista de agosto de 2011: "Nosotros también somos resistencia indígena” (28 páginas).

- Revista de noviembre de 2011: "En Colombia crece la lucha de masas" (40 páginas).

- Revista de diciembre de 2011, en homenaje a "Alfonso Cano" (68 páginas).

- Revista de marzo de 2012: "Una evocación de nuestros mártires" (36 páginas).

- Revista de abril de 2012, en homenaje al "Día del Derecho Universal de los pueblos a la rebelión armada” (47 páginas).

Las ediciones fueron consultadas en el sitio web del grupo insurgente (se las puede consultar siguiendo el enlace que aparece en la referencia FARC, 2015). El contenido de las revistas fue procesado en el software Atlas.ti 6.2, con el cual se realizó un análisis basándose en procedimientos propuestos por la teoría fundamentada (Strauss y Corbin, 2002) y el análisis del discurso (Arnoux, 2009). En cuanto a la teoría fundamentada, se desarrolló una codificación abierta in vivo y otra codificación axial. La primera hace referencia a la identificación de los términos del corpus (palabras, sintagmas, construcciones y segmentos), donde emergieron reformulaciones polémicas, de acuerdo con el sustento teórico antes descrito. Esta codificación permitió ver y nombrar con etiquetas provisionales las propiedades (características) y variaciones de los datos, para identificar los modos en que se presenta el concepto de 'reformulación polémica' en ellos. La segunda, codificación axial, se refiere a la construcción de relaciones entre los códigos asignados en el paso anterior en torno al eje conceptual ya definido. Aquí se enlazaron las propiedades y variaciones de las categorías, como 
modos de construcción de la modalidad argumentativa polémica en el discurso guerrillero.

Posteriormente, con el corpus codificado, se aplicó un proceso analítico inferencial de indicios o huellas de regularidades, a través del cual el procedimiento abductivo (encadenamiento de hipótesis a partir de confrontaciones con los textos del corpus) permitió identificar, describir y relacionar esas huellas como "indicios reveladores de alguna regularidad significativa” (Arnoux, 2009, pp. 13-29). De esta forma, se determinaron las categorías emergentes para describir las regularidades a las que hemos denominado de cuatro modos distintos, de acuerdo con los usos de la reformulación polémica en el discurso de las FARC, y los cuales conforman la siguiente sección de resultados.

\section{Resultados}

En los diversos géneros textuales que circulan en la revista Resistencia aparecen tres formas de reformulación polémica: definitoria, modal y contrastiva. La primera se refiere a la desacreditación del discurso del adversario a través de la postulación de definiciones sobre lo real y lo verdadero; la modal se concentra en desacreditar el estilo verbal y los recursos léxicos del discurso con el que se polemiza; la contrastiva consiste en el uso marcado del contraste entre perspectivas en divergencia, para realzar el punto de vista propio. Además de estas tres formas, se encontró que la reformulación polémica puede aparecer reforzada por el uso de la negación polifónica ( $\mathrm{Du}$ crot, 1985, García Negroni, 2009), como se explicará más adelante. Esta clasificación no pretende ser exhaustiva, sino ilustrativa de la exploración realizada en el corpus acotado. ${ }^{9}$

El criterio de esta clasificación, que servirá para presentar las categorías emergentes del análisis del corpus (como se mencionó en el apartado metodológico), es el énfasis sobre lo cual la enunciación polémica ejerce una

9 En el trabajo de Steuckardlt (2009, p. 170), en cambio, sí se encuentra la preocupación por establecer una tipología de la reformulación polémica. La menciono aquí a modo de información, pero no será utilizado en el análisis del corpus para este artículo: reformulación especificativa $(\mathrm{X}>\mathrm{Y})$, generalizadora $(\mathrm{X}<\mathrm{Y})$, descalificadora $(\mathrm{X}+/ \mathrm{Y}-, \mathrm{o}$ bien, $\mathrm{X}=/ \mathrm{Y}-)$ y recalificadora $(\mathrm{X}-/ \mathrm{Y}+)$. 
desacreditación, ${ }^{10}$ es decir, la orientación que presenta cada forma de desacreditar al adversario. Los operadores gramaticales de esas formas de desacreditación no son fijos (no tienen correspondencia unívoca con cada tipo de reformulación) ${ }^{11}$ ni excluyentes (pueden aparecer combinados en cada enunciado), pero sí comparten rasgos funcionales de orden gramatical y semántico. A continuación, se explica cada modo de reformulación y se ilustra cómo van apareciendo articulados entre sí en algunos casos puntuales, con lo cual se deja claro que no se trata de una tipología con miembros excluyentes, sino de formas diversas de énfasis en la desacreditación del discurso del adversario: característica de la polémica como modalidad argumentativa (Amossy, 2014, pp. 61-63).

\section{La reformulación polémica definitoria}

La reformulación se concentra en la desacreditación de conceptos o nociones presentes en la predicación del adversario. Se distingue por el uso explícito de verbos atributivos, en los cuales recae la intención de redefinir un segmento de lo real o lo verdadero, que entra en disputa. Ejemplos:

[1] El mencionado investigador no sabe qué es el Nuevo Modo de Operar y asombrosamente dice que es una modalidad adoptada por las FARC en 1995. En realidad el Nuevo Modo de Operar fue una directriz emanada de la VII Conferencia de las FARC, que tuvo lugar en la región de El Duda en 1982 (FARC, Revista Resistencia, mayo de 2010, p. 5).

Desacreditar el "saber" del otro le permite a su contradictor instalar una versión de la realidad en forma de revelación, es decir, de verdad descubierta y, por tanto, única. Así, los verbos atributivos inclinan la enunciación hacia una lógica apofántica donde definir qué es lo verdadero y qué es lo falso termina siendo fundamental para ganar la confianza y credibilidad del auditorio. Los subrayados indican los recursos gramaticales que

10 Si bien los términos descalificación y desacreditación suelen utilizarse como sinónimos en los estudios sobre la polémica, privilegio el uso del segundo para hacer mayor énfasis en la creencia y confianza que resultan afectadas al desacreditar al adversario, de acuerdo con la asociación etimológica (Corominas, 1987, p. 177).

11 Es necesario aclarar que ninguna de las piezas lingüísticas analizadas es unívoca en su significado ni en su función discursiva, y que, por tanto, existe polivalencia respecto de posibles orientaciones del sentido. Aquí se ofrece una interpretación plausible de esos enunciados, desde el punto de vista de la polémica como modalidad argumentativa (Amossy, 2014) y de las huellas que deja la inscripción de oposiciones políticas en el discurso. 
funcionan como reformuladores polémicos; todos ellos enfatizan una (re) definición de la realidad por medio del verbo atributivo, como sucede en:

“... El mencionado investigador no sabe qué es...”.

“... asombrosamente dice que es...”.

“... En realidad, el nuevo modo de operar fue...”.

En el último caso, la locución adverbial "En realidad" establece el cambio de definición del tema tratado (¿qué es el nuevo modo de operar?), contrastando la definición atribuida al adversario ("el mencionado investigador") con la que presenta el discurso guerrillero como verdadera, real ("el nuevo modo de operar fue una directriz ..."). Esa función de enfatizar el contraste aparece aquí reforzando la definición marcada con el verbo atributivo (su funcionamiento contrastivo será ampliado más adelante, en la denominada reformulación polémica contrastiva).

En [2] se presenta también énfasis con el verbo ser:

[2] Afirmar ahora [...] que la imposibilidad de derrotar a la insurgencia es por causa de la incapacidad del saliente comandante de las Fuerzas Militares [...] es buscar el ahogado aguas arriba y pensar con el deseo. Es además cinismo puro, pues se intenta manipular groseramente la realidad (FARC, Revista Resistencia, agosto de 2011, p. 28).

El uso de la atribución es contundente para redefinir no solo una realidad objetiva o externa a los actores, sino también lo que ellos mismos "son", "hacen" y “dicen". En [2], por ejemplo, el descrédito de lo que el adversario afirma se refuerza con la ridiculización, el juicio de valor y los términos valorativos $^{12}$ introducidos (señalados con cursiva). Los ejemplos [1] y [2] dejan ver, además, que reformular redefiniendo lo que el adversario afirma es, sobre todo, acusarlo de infidelidad frente a la realidad objetiva, esto es, de faltar a una "verdad esencial". El papel de los verbos atributivos en la reformula-

12 Por cuestión de espacio y de focalización, en este artículo no incluyo el análisis de los términos valorativos ni del sistema de valoración en general, para concentrarme en la explicación del procedimiento de la reformulación polémica, pese a que puede explorarse una relación estrecha entre ambos procedimientos retóricos. Dejo pendiente este aspecto para futuros trabajos. 
ción polémica definitoria es, entonces, desde el punto de vista semántico, postular un nuevo estatuto de lo real y lo verdadero (lo que "es"); desde lo pragmático, introducir ese estatuto a través de los actos de habla "definir" y "redefinir"; y desde lo argumentativo, hacer funcionar el enunciado definitorio con la lógica de la polémica, a través de la cual se desacredita el punto de vista del adversario en el espacio público.

\section{La reformulación polémica modal}

La reformulación se concentra en la desacreditación del estilo y de los recursos léxicos usados por el adversario. Se distingue por la dimensión metarretórica que asume la enunciación al introducir los modos del decir en los juegos de lo verdadero y lo falso. Ejemplos:

[3] La enrevesada explicación del ministro de Defensa [...] de que no se trató de un operativo de rescate, sino de búsqueda, no es más que un precario eufemismo que no alcanza a tapar la perfidia de un gobierno ni su desprecio a normas esenciales del Derecho Internacional Humanitario (FARC, Revista Resistencia, diciembre de 2011, p. 37).

En estos casos, reformular es "quitar los adornos" del decir del adversario para revelar lo que ocultan esos decorados; así, el fragmento [3], que incluye un uso del verbo atributivo "ser" que funciona como se explicó en el apartado anterior (al establecer definiciones de la realidad), contiene además una especie de "deseufemización", en la cual la guerrilla se posiciona como el sujeto que es capaz de decir la verdad. Krieg-Planque (2004), en este misma perspectiva, atribuye a ese señalamiento de eufemismos una función de posicionamiento social en el orden del discurso político, soportado sobre sistemas de valores particulares. Esa "toma de postura", en la retórica guerrillera, es también una "impostura" como denunciantes de las argucias del adversario. En todos los ejemplos encontrados, se hace hincapié en la intencionalidad y el reproche de ese ocultamiento que estaría ejerciendo el Gobierno colombiano:

[4] ... para seguir con el pretendido afianzamiento de lo que llaman "confianza inversionista" a través de los nefandos métodos de la ya conoci- 
da "seguridad democrática", o "prosperidad democrática", o como le quieran llamar a la militarización mayor de la vida nacional y al trato guerrerista a las acciones de masas (FARC, Revista Resistencia, noviembre de 2011, p. 13).

En [4] se ejemplifica el uso recurrente de las comillas con la doble función de marcar los límites entre la palabra ajena y la propia, y traer fielmente a escena el discurso del adversario ("heterogeneidad mostrada", en términos de Authier-Revuz, 1984), pero también de ironizarlo al contradecir el contenido de las nominalizaciones cuando se reformula la "seguridad democrática" como "militarización" y la "prosperidad democrática" como "trato guerrerista". Desacreditar el modo en que el adversario nombra la realidad es acusarlo de ser retórico, en el sentido más peyorativo posible, es decir, de engañar y manipular con su palabra sin ningún escrúpulo frente a la verdad.

\section{La reformulación polémica contrastiva}

La reformulación se concentra en la desacreditación del punto de vista del adversario. Se distingue por la marcación de un posicionamiento opuesto al refutado y por el uso de reformuladores de rectificación (Cortés y Camacho, 2005; Zorraquino y Portolés, 1999), en los cuales se apoya el disidente para contrastar y relevar su propio punto de vista. Ejemplos:

[5] La paz en Colombia no nacerá de ninguna desmovilización guerrillera, sino de la abolición definitiva de las causas que dan nacimiento al alzamiento (FARC, Revista Resistencia, noviembre de 2011, p. 29).

La reformulación anula y corrige el segmento anterior al operador reformulativo y reorienta la argumentación hacia tesis alternativas a las propuestas por el adversario. En el caso de [5], los puntos de vista contrastados se refieren al mismo asunto (la paz), pero a dos modos distintos de tratarlo: en el discurso reformulado, como efecto de la desmovilización guerrillera, y en el discurso reformulante, como efecto de la abolición de las causas que originan la rebelión armada. Se trata, pues, de casos de reformulación, donde el asunto se conserva, pero se desacredita un punto de vista para introducir otro que lo contradice explícitamente. Este funcionamiento descrito 
ya lo habíamos visto aparecer integrado en el ejemplo [1], como refuerzo de una reformulación polémica definitoria. En [6] se ejemplifica de nuevo ese contraste:

[6] Los planes del gobierno Santos ni son para la prosperidad ni mucho menos representan la democratización del país, en cambio, sí son la profundización del neoliberalismo y la seguridad fascista (FARC, Revista Resistencia, mayo de 2010, p. 23).

Aquíse pone en contradicción la "prosperidad" yla "democratización" con el "neoliberalismo" y la "seguridad fascista", como sus opuestos directos. El operador reformulativo orienta el sentido de la antonimia construi$\mathrm{da}$, a través de la cual prosperidad y neoliberalismo quedan posicionados en orillas opuestas, lo mismo que democracia y seguridad, reforzados por el calificativo "fascista".

\section{La negación polifónica como refuerzo}

Como se anunció más atrás, la reformulación polémica puede aparecer reforzada por la denominada "negación polifónica". En los ejemplos [1], [3], $[5]$ y $[6],{ }^{13}$ se pueden encontrar negaciones que operan dentro o en función de cada reformulación; en el corpus analizado, es común encontrar estas coocurrencias entre modos de reformulación polémica y formas negativas marcadas, ambos procedimientos pertenecientes al nivel retórico de los enunciados. Para Ducrot (1985), la negación, cuando no es solo descriptiva, evidencia siempre el choque entre dos puntos de vista antagónicos, pertenecientes a sujetos discursivos distintos (de ahí que el autor las denomine "negaciones polifónicas", es decir, con presencia de múltiples voces relacionadas). Desde la relectura de García Negroni (2009), existe un tipo de negación polifónica que rechaza y desacredita un determinado marco de discurso en favor de otro, produciendo efectos constrastivos ("negar $\mathrm{X}$ es decir lo contrario de X"), ascendentes ("negar X es decir mucho más

13 La negación en el ejemplo [6] está marcada por la conjunción copulativa negativa ni: "Los planes del gobierno Santos ni son para la prosperidad ni mucho menos representan la democratización del país...”; negación que se ve enfatizada a través del adverbio de afirmación sí, precedido del operador reformulativo de rectificación en cambio. 
que X") o diferenciales ("negar X es decir Y"). García Negroni (2009, p. 79) llama "negación metalingüística" a este tipo de negaciones, cuya "función fundamental es la de permitir la instauración de un nuevo marco o espacio de discurso presentado por el locutor como el único adecuado para la caracterización argumentativa de la situación de la que habla”. En [7] se ejemplifica un caso de negación con efecto contrastivo:

[7] [una] prosperidad excluyente que no se propone liberar de la pobreza al $70 \%$ de la población que la padece, sino la progresión de las ganancias de las élites, del sector inversionista, de los banqueros y los grandes empresarios (FARC, Revista Resistencia, mayo de 2010, p. 43).

La desacreditación del marco de discurso previo al reformulador "sino" se realiza instaurando un marco nuevo, donde la política criticada no ayuda los pobres, sino que aumenta la riqueza de las élites. En el corpus analizado, frecuentemente las diferentes negaciones polifónicas sirven de soporte para las reformulaciones polémicas, toda vez que hacen hincapié en la desacreditación del adversario y orientan la atención hacia los segmentos reformulantes.

La combinación de diversas reformulaciones polémicas soportadas por el recurso de la negación polifónica estructura la construcción de la oposición política en el discurso guerrillero, orientada hacia la desacreditación de lo que el adversario asegura como verdadero:

[8] ¿ Pretende acaso el Ministro hacerle creer a la sociedad colombiana que después de más de 50 años de confrontación armada, sólo hay en Colombia Prisioneros de las fuerzas oligárquicas? Existimos [...], somos parte fundamental a tener en cuenta en la inaplazable tarea de enrumbar el país por el camino de la reconciliación nacional. Otra cosa muy diferente es que al gobierno no le interese transitar por tan noble ruta, sino por el contrario por el de la sangre y la perfidia (FARC, Revista Resistencia, marzo de 2012, p. 5).

Los operadores reformulativos en [8] pretenden redefinir creencias y contrastar versiones opuestas del conflicto: al punto de vista del Gobierno se le asocia con "la sangre y la perfidia", mientras que la guerrilla se le 
opone con la perspectiva de "la reconciliación nacional". La negación subrayada al final soporta la introducción de esas reformulaciones definitorias y contrastivas.

Si bien se presentan coocurrencias entre reformulaciones polémicas y negaciones metadiscursivas, en los ejemplos expuestos antes de este apartado queda en evidencia que no toda reformulación polémica se realiza a través de una negación; es decir que esta última no es una condición ni necesaria ni suficiente para introducir la modalidad polémica en las operaciones reformuladoras.

\section{Conclusiones}

A través de un análisis de textos publicados por la guerrilla de las FARC en su revista Resistencia (ediciones 2010 a 2012), se exploró un conjunto de formas enunciativas en las que aparece el procedimiento retórico de la reformulación polémica (Steuckardtl, 2007, 2009). El corpus conformado es, entonces, el origen de cada uno de los conceptos esbozados, a los cuales se propuso denominar como reformulaciones polémicas definitoria, modal y constrastiva.

En todas ellas, el segundo segmento retoma al primero, lo "vuelve a decir" aparentemente de modo parafrástico, pero reorientando la interpretación del sentido. En la reformulación polémica definitoria, el énfasis recae sobre la desacreditación del discurso del adversario a través de la implantación de definiciones de lo real y lo verdadero, distintas al decir con el cual se polemiza. En la reformulación polémica modal, se hace hincapié en desacreditar al otro criticando su estilo y sus recursos léxicos, es decir, se atiende principalmente a lo metalingüístico y metarretórico. En la reformulación polémica constrastiva, la desacreditación se dirige directamente hacia el punto de vista del adversario y se utiliza el constraste que otorgan los marcadores de rectificación y de contraargumentación para realzar el punto de vista propio. Estos modos de reformulación polémica no son exhaustivos ni conforman una tipología, aparecen constantemente articulados entre sí en el discurso guerrillero estudiado y su dimensión polémica se ve reforzada por su coocurrencia con el procedimiento de la negación polifónica (Ducrot, 1985; García Negroni, 2009). 
La observación de estos casos de modos reformulativos en clave polémica no pretende agotar lo clasificatorio ni proponer una abstracción de macroestrategias lingüísticas en el discurso guerrillero, pues esa pretensión desborda el corpus utilizado en esta aproximación. En cambio, los ejemplos provistos permiten ver cómo el discurso guerrillero utiliza la reformulación polémica para presentarse a sí mismo de una manera particular: como el discurso aclarativo y revelador, que se arroga el derecho y el deber de desacreditar al discurso oficial y, con ello, construir polémicas públicas en torno a la realidad y la verdad en medio del conflicto armado.

La polémica se concentra, así, en la desacreditación del adversario político (en este caso, el discurso oficial) cuando se deja al descubierto el supuesto sentido oculto de lo que cree, dice y hace. Las relaciones oposicionales son construidas en y por el discurso, categorizando y recategorizando al adversario y a sí mismo a través de nominalizaciones que se enfocan en una redefinición de la realidad (reformulación polémica definitoria), en la crítica al modo de presentarla (reformulación polémica modal) o en el contraste entre puntos de vista divergentes (reformulación polémica contrastiva).

En clave política, la reformulación polémica lleva al centro de las cuestiones del conflicto armado el problema de las polémicas en torno a la definición de las situaciones, la veracidad o la manipulación engañosa en cada discurso armado (oficial e insurgente) y la contraposición de puntos de vista, esto es, la determinación de quién dice la verdad y, sobre todo, de quién es capaz de revelarla. ${ }^{14}$ Cuando el discurso guerrillero hace aparecer estos modos de reformulación, asume la tarea política de polemizar, controvertir y desacreditar al discurso oficial, y de difundir ese discurso polémico en el espacio público a través de su revista. La guerrilla construye así una disposición o posicionamiento con respecto a lo que asume, presenta y defiende como verdad, en oposición a la supuesta mentira del adversario.

14 Al "desenmascarar" la palabra del adversario y hacer aparecer en el espacio público aquello que su discurso ha ocultado por conveniencia, la reformulación hace correr también conscientemente un riesgo por el cual el reformulador está dispuesto a sacrificarse a sí mismo: el riesgo de "decir la verdad”. En el antiguo sistema democrático griego, esa función política del "decir verdadero" que pone en riesgo al sujeto que la asume, fue conocida como parresía. Foucault (2004 [1983], p. 56) la define como "una actividad verbal en la que un hablante expresa su relación personal con la verdad, y arriesga su propia vida porque reconoce el decir la verdad como un deber para mejorar o ayudar a otras personas". Dejo apenas indicada y sin desarrollar esta reflexión, que permitiría pensar posibles relaciones entre reformulación polémica, parresía y sujetos del decir verdadero. 
Los tipos de reformulación polémica son entonces: 1) medios retóricos con los cuales el disidente acusa públicamente a su adversario de falsear la realidad y de ocultarla bajo palabras manipuladoras, es decir, modos de construir oposiciones políticas en el discurso desde la desacreditación del enemigo, y 2) medios retóricos con los cuales el disidente construye una relación de sí mismo con la "verdad" que enuncia y bajo la cual queda políticamente comprometido como sujeto que define "en realidad" qué es lo que sucede (en el orden de la definición), cómo engaña el adversario (en el orden de su manipulación con el lenguaje) y cuál es su "verdadero" punto de vista (en el orden del contraste con la perspectiva propia).

La reformulación polémica es clave, pues, en el esfuerzo del discurso guerrillero por construir una divergencia política más allá de la violencia física; de ahí que pueda rastreársele como una regularidad en los textos de su órgano ideológico de difusión masiva, la revista Resistencia. Como procedimiento retórico, la reformulación polémica refuerza el distanciamiento entre los discursos de los actores, al introducir el problema de la verdad como objeto de disputa y como motivo principal de la polémica pública. Esperamos haber sugerido que el análisis de un procedimiento lingüístico con función retórica, como el de la reformulación polémica, es una entrada productiva para el desarrollo de reflexiones políticas futuras en este sentido.

\section{Referencias}

Amossy, R. (2014). Apologie de la polémique. París: PUF.

Angenot, M. (1982). La parole pamphlétaire. París: Payot.

Arnoux, E. (2009). Análisis del discurso: modos de abordar materiales de archivo (2. a ed.). Buenos Aires: Santiago Arcos.

Authier-Revuz, J. (1984). Hétérogénéité(s) énonciative(s). Langages, 73, 98-111. 
Bosque, I. (2001). Prólogo. En E. Montolío, Conectores de la lengua escrita (pp. 9-14). Barcelona: Ariel.

Briz, A. (2008). Diccionario de partículas del español. Alicante : Biblioteca Virtual Miguel de Cervantes.

Casado, M. (1991). Los operadores discursivos es decir, esto es, o sea y a saber en el español actual: valores de lengua y funciones textuales. LEA, XIII, 87-116.

Charaudeau, P. y Maingueneau, D. (2005). Diccionario de análisis del discurso. Buenos Aires: Amorrortu.

Charolles, M. (1987). Spécialisation des marqueurs et spécificité des opérations de reformulation, de dénomination et de rectification. En P. Bange (ed.), L'analyse des interactions verbales (pp. 99-122). Berne: Peter Lang.

Corominas, J. (1987). Breve diccionario etimológico de la lengua castellana (3. ${ }^{\text {e }}$ d.). Madrid: Gredos.

Cortés, L. y Camacho, M. (2005). Unidades de segmentación y marcadores del discurso. Madrid: Arco Libros.

Ducrot, O. (1985). El decir y lo dicho. Buenos Aires: Hachette.

FARC (2015). Revista Resistencia. Ediciones de mayo de 2010; junio, julio, agosto, noviembre y diciembre de 2011; enero, marzo y abril de 2012. Recuperado el 22 de mayo de 2015 de https://resistenciacolombia.org/index.php/FARC-ep/revista-resistencia/b-mc-ir

Foucault, M. (2004 [1983]). Discurso y verdad en la antigua Grecia. Buenos Aires: Paidós.

Fuentes, C. (1993). Conclusivos y reformulativos. Verba, 20, 171-198. 
Fuentes, C. (2009). Diccionario de conectores y operadores del español. Madrid: Arco Libros.

Galán, C. (1998). La dimensión explicativa y deóntica de los conectores o sea y es decir. Anuario de Estudios Filológicos, XXI, 85-104.

Garcés, M. (2006). Las operaciones de reformulación. En M. Villayandre (ed.), Actas del XXXV Simposio Internacional de la Sociedad Española de Lingüística (pp. 654-672). Recuperado el 22 de mayo de 2015 de http://fhyc.unileon.es/SEL/actas/Garces.pdf

Garcés, M. (2008). La organización del discurso: marcadores de ordenación y de reformulación. Madrid/Fráncfort: Vervuert.

García Negroni, M. (2009). Negación y descalificación. A propósito de la negación metalingüística. Ciências \& Letras, 45, 61-82.

García Negroni, M. (ed.) (2014). Marcadores del discurso: perspectivas y contrastes. Buenos Aires: Santiago Arcos.

Grice, P. (1989 [1975]). Logic and conversation. En P. Grice, Studies in the way of words (pp. 22-40). Cambridge/Londres: Harvard University Press.

Kerbrat-Orecchioni, C. (1980). La polémique et ses definitions. En N. Gelas y C. Kerbrat-Orecchioni (eds.), Le discourse polémique (pp. 3-40). Lyon: Presses Universitaires de Lyon.

Kotschi,T.(2001).FormulierungspraxisalsMittelderGesprächsaufrechterhaltung. En K. Brinker (ed.), Text-und Gesprächslinguistik (pp. 1340-1348). Berlín/Nueva York: Walter de Gruyter.

Krieg-Planque, A. (2004). Souligner l'euphémisme: opération savante ou acte d'engagement? Analyse du «jugement d'euphémisation» dans le discours politique. Semen, 17. Recuperado de http://semen.revues.org/2351 
Loureda, Ó. y Acín, E. (coords.) (2010). Los estudios sobre marcadores del discurso en español, hoy. Madrid: Arco/Libros.

Montolío, E. (2001). Conectores de la lengua escrita. Barcelona: Ariel.

Olave, G. (2011). Los marcos del conflicto: aproximación al conflicto armado colombiano desde el concepto de marco. Discurso \& Sociedad, 5(3), 514-546. Recuperado de http://www.dissoc.org/ediciones/ v05n03/DS5(3)Olave.html

Olave, G. (2012). La construcción retórica del conflicto armado colombiano: metáfora y legitimación del carácter bélico del conflicto. Signos, Estudios de Lingüística, 45(80), 300-321. Recuperado de http://www.scielo.cl/scielo.php?script=sci_arttext\&pid=S071809342012000300004\&lng=es\&nrm=iso\&tlng=es

Olave, G. (2013a). Dramática del discurso de la paz en Colombia. Diálogos Estado-FARC, 2012. En N. Pardo (coord.), Estudios del discurso en América Latina (pp. 257-282). Bogotá: Asociación Latinoamericana de Estudios del Discurso. Recuperado el 22 de abril de 2015 de http://aledportal.com/descargas/libroAMH_baja.pdf

Olave, G. (2013b). La argumentación epidíctica en el discurso político del conflicto armado colombiano contemporáneo. En P. Salazar y A. Vitale, Rhetoric of South America (pp. 257-282). Cape Town, Suráfrica: Africa Rhetoric Publishing. Recuperado el 7 de abril de 2015 dehttp://africanrhetoric.org/pdf/7_Olave_Rhetoric\%20in\%20 South\%20America.pdf

Olave, G. (2014). Aproximaciones retóricas al conflicto armado colombiano: una revisión bibliográfica. Forma y Función, 27(1), 155-197.

Olave, G. (2015a). Elogio político y argumentación en los discursos presidenciales de Juan Manuel Santos. En E. N. Arnoux y V. Zaccari, Discurso y política en Sudamérica (pp. 279-358). Buenos Aires: Biblos. 
Olave, G. (2015b, 24-26 de junio). De la oposición política en el discurso: el caso de la reformulación polémica en la retórica guerrillera colombiana. Congreso Internacional de Retórica e Interdisciplina: La cultura y sus retóricas. Villa María, Córdoba, Argentina.

Olave, G. (2015c). Decir lo que el adversario calla: el problema de la indecibilidad en el conflicto armado colombiano. Asociación Latinoamericana de Estudios del Discurso, 15(2). En prensa.

Olave, G. y Cediel, Y. (2015). ¿"Acuerdos” o “capitulaciones”? Retórica de la oposición al proceso de paz entre el Gobierno y las FARC en 2014. Cuadernos del Gescal, 2(1), 57-72.

Plantin, C. (2003). Des polémistes aux polémiqueurs. En G. Declercq, M. Murat y J. Dangel (eds.), La parole polémique (pp. 377-408). París: Champion.

Pons, S. (2000). Los conectores. En A. Briz (ed.), Cómo se comenta un texto coloquial (pp. 193-220). Barcelona: Ariel.

Roulet, E. (1987). Complétude interactive et connecteurs reformulatifs. Cahiers de linguistique française, 11, 111-140.

Rossari, C. (1997). Les opérations de reformulation. Berne: Peter Lang.

Steuckardtl, A. (2007). Usages polémiques de la reformulation. Recherches linguistiques, 29, 55-74.

Steuckardlt, A. (2009). Décrire la reformulation. Le paramètre rhétorique. Cahiers de Praxématique, 52, 159-172.

Srauss, A. y Corbin, J. (2002). Bases de la investigación cualitativa: técnicas y procedimientos para desarrollar la teoría fundamentada. Medellín: Editorial Universidad de Antioquia. 
Vercruysse, A. (2009). Un estudio de algunos reformuladores en español: a saber, esto es, es decir, o sea, mejor dicho (Tesis de maestría, Universiteit Gent).

Wilson, D. y Sperber, D. (2006). Relevance Theory. En L. Horn y G. Ward, The handbook of pragmatics (pp. 607-632). Malden: Blackwell Publishing.

Zorraquino, M. y Portolés, J. (1999). Los marcadores del discurso. En I. Bosque y V. Demonte (eds.), Nueva gramática descriptiva de la lengua española, 3 (pp. 4051-4213). Madrid: Espasa-Calpe. 